\title{
Effect of group open-book assessment on students' learning and satisfaction: a quasi-experimental study
}

\author{
Farin Tatari', Hosnieh Raoufian², Monireh Mashhadi ${ }^{3}$, Akram Gazerani ${ }^{4}$ \\ ${ }^{1}$ Department of Public Health, Neyshabur University of Medical Sciences, Neyshabur, Iran \\ 2Department of Operating Room and Anesthesia, School of Nursing and Midwifery, North Khorasan University \\ of Medical Sciences, Bojnurd, Iran \\ ${ }^{3} \mathrm{MSc}$, Medical-Surgical Nursing, Yazd University of Medical Sciences, Yazd, Iran \\ ${ }^{4}$ Department of Operating Room and Anesthesia, Neyshabur University of Medical Sciences, Neyshabur, Iran
}

Neuropsychiatria i Neuropsychologia 2021; 16, 1-2: 87-91

Address for correspondence:

Akram Gazerani, MSc

Department of Operating Room and Anesthesia

Neyshabur University of Medical Sciences

Neyshabur, Iran

e-mail: Gazerania1@nums.ac.ir

\begin{abstract}
Introduction: Effective assessment is one of the most important educational planning elements. The present study aimed to determine the impact of open-book assessment on students' learning and satisfaction.

Material and methods: This study was a quasi-experimental study on $604^{\text {th }}$ semester students of operating room and anesthesiology of the North Khorasan University of Medical Sciences, North of Iran from 1 July 2019 to 30 March 2020. In the intervention group, the students were divided into groups of five and were given essay questions and a textbook on blood transfusion, and were asked to answer the questions in a participatory and open-book assessment method. In the control group, the assessment was performed in a separate environment by a written method with the same essay questions as the intervention group.

Results: The results showed that $89 \%$ of the students in the intervention group were satisfied with the openbook assessment method. The majority of students found this method effective in reducing test fear and anxiety (93.4\%), increasing durability and depth of learning (90\%), improving speed and facilitating learning (80\%) and creating interest and satisfaction (89\%) and reported completely agree. The mean score of students in the intervention group was $4.5 \pm 0.77$ and in the control group was $2.2 \pm 0.85$, which was statistically significant $(p=0.01)$. Conclusions: The open-book assessment method leads to the students' active participation in studying and answering questions. It also facilitates deep learning, reduces anxiety, and improves the students' learning speed. Universities should promote students' learning, academic achievement, and motivation through innovative assessment methods.
\end{abstract}

Key words: academic success, personal satisfaction, motivation, students.

\section{Introduction}

Promoting the educational quality of universities is an important issue that has been emphasized in recent years (Assadi et al. 2014). New approaches to research in education focus on the use of learning and study strategies to facilitate the learning process and ultimately enhance academic achievement (Klieme 2020). The importance of using strategies to promote education is well recognized (Shahidi et al. 2005). Assessment, which is a systematic process of collecting, analyzing, and interpreting data for evaluation and judgment, is one of the most important pillars of educational planning
(Alghamdi 2020). Assessment not only plays a significant role in differentiating students, but it can also identify the educational program's weaknesses and strengths and provide an appropriate solution to educational program problems (Coker et al. 2015).

Also, evaluation is an integral part of the teaching-learning process that is carried out continuously along with education and interconnects with it and focuses on the learning direction of learners (Feldhusen 1961). In desirable learning situations, evaluation and education processes are inextricably linked (Atashrouz et al. 2018; Crooks 1988). This point that is emphasized by psychological and educational assessment 
specialists, emerging from new perspectives and new evaluation methods, affirms that the final goal of both of them must be learners' learning, growth, and development (Pakkies and Mtshali 2016). Evaluation pursues several goals, such as student rating, understanding of their educational problems, evaluation of the teaching methods used, and lesson or course success rate. Students' evaluation is important because it confirms their competence (Crooks 1988).

Assessment is also important in terms of time because by doing it only at the end of the semester through summative assessment, the students will not have the opportunity to identify their mistakes or try to correct them. Therefore, formative assessment can also be used for continuous assessment throughout the semester (Komeili and Rezai 2001).

There are various methods for assessing learners, such as multiple-choice tests, oral tests, essay tests, work-based tests, etc.; all the aforementioned methods have advantages and disadvantages (Durning et al. 2016; Haghshenas et al. 2009). Teachers should choose the best method from different assessment methods, according to their educational objectives (Haghshenas et al. 2009). One of the types of assessment methods is the open-book method whereby the teacher provides the learners with an opportunity to use the textbook and other relevant resources individually or in a group. The open-book method, if properly designed and performed, is one of the most important and prominent examples of creative assessment (Durning et al. 2016).

Generally, the open-book method encourages students to perform deep learning and achieve higher cognitive levels (Durning et al. 2016). The use of the open-book method seems to be better aligned with the learning goals as it reduces the need to learn and remember a lot (Eilertsen and Valdermo 2000; Msila 2011).

Also, this type of assessment can have benefits such as reducing anxiety, increasing reminders, and reducing cheating (Abdollahi $e t$ al. 2015). Eilertsen and Valdermo (2000) believe that open-book assessment enables students to become more involved and better understand the course topics.

According to the above, this study was conducted to determine the impact of open-book assessment on students' learning and satisfaction.

\section{Material and methods}

This study was a quasi-experimental study on $604^{\text {th }}$ semester students of operating room and anesthesiology of North Khorasan University of Medical Sciences, North of Iran from 1 July 2019 to 30 March 2020. Students were selected using the convenience sampling method and randomly assigned to control and intervention groups. The purpose of the research and the confidentiality of the information were explained to the students. Their participation in the research was voluntary, and if they wished, they were allowed to exit the study. A demographic questionnaire including age, sex, marital status, educational discipline, semester and residence status was used to collect demographic data. A pre-test was taken of all students to check students' information about blood transfusion and its care before the workshop. Then blood transfusion topics were taught to all students. On the cards were written numbers one (intervention group) and two (control group) and the research units randomly selected one card and were randomly divided into intervention (open group assessment) and control groups (usual written test assessment method). In the intervention group, the students were divided into groups of five and were given essay questions and a textbook on blood transfusion, and were asked to answer the questions in a participatory and open-book assessment method. In the control group, the assessment was done separately with the same questions in a different location. The questions were designed to assess high levels of cognitive learning using long-answer essay questions. After one week, the assessment was performed through multiple-choice questions for all 60 students. Also, the effect of openbook assessment method on students' depth of learning, exam fear and anxiety, interest, and satisfaction was assessed by a Likert scale questionnaire from strongly agree (Coker et al. 2015) to strongly disagree (Assadi et al. 2014). The questionnaire used in this study was a researcher-made questionnaire, whose validity was achieved using the articles and comments of the relevant faculty members, and its validity was confirmed by 10 expert faculty members. Reliability was also measured in a preliminary study using Pearson's correlation coefficient.

\section{Ethical considerations}

This study was approved by the Ethics Committee of North Khorasan University of Medical Sciences and the Ethics Committee of the place where research was conducted (Ethic code: IR.NKUMS.REC.1399.039). 


\section{Statistical analysis}

After data entry and control of data entry accuracy, data analysis was performed with SPSS 21 software. Descriptive statistics of mean, standard deviation, and frequency distribution were used to describe the characteristics of research units. $T$-test and paired $t$-test were used for data analysis of intervention and control groups. 95\% confidence coefficient and $5 \% p$-value were considered.

\section{Results}

The results showed that $50 \%(n=30)$ were anesthesiology students and $50 \%(n=30)$ were operating room students. Their mean age was $21 \pm 2$. No significant relationship was found between the variables of age, sex, marital status, educational discipline, and residency status in the control and intervention groups (Table 1 ).

Findings of the effect of the open-book assessment method by the questionnaire showed that $89 \%$ of the students in the intervention group had a high level of satisfaction with this assessment method, which indicates a high level of learners' satisfaction.

The majority of students found this method effective in reducing test fear and anxiety (93.4\%), increasing durability and depth of learning (90\%), improving speed and facilitating learning $(80 \%)$ and creating interest and satisfaction $(89 \%)$, reporting strongly agree $(p=0.01)$ (Table 2).

The results also showed that the intervention group received higher scores on the multiplechoice test than the control group. The mean score of students in the intervention group was $4.5 \pm 0.77$, and in the control group was 2.2 \pm 0.85 , and this difference was statistically significant (Table 3).
Table 1. Students' demographic information

\begin{tabular}{lcc}
$\begin{array}{l}\text { Demographic } \\
\text { characteristics }\end{array}$ & $\begin{array}{c}\text { Frequency } \\
\text { (frequency percent) }\end{array}$ & $p$-value \\
\begin{tabular}{l} 
Sex \\
\hline Male
\end{tabular} & 0.05 \\
\hline Female & $11(18.4 \%)$ & \\
\hline Marital status & $49(81.6 \%)$ & \\
\hline Married & $14(23.4 \%)$ & \\
\hline Single & $45(75 \%)$ & \\
\hline Divorced & $1(1.6 \%)$ & \\
\hline Semester - 4 & 60.492 \\
\hline Educational discipline & & \\
\hline Operating room & $30(50 \%)$ & 0.05 \\
\hline Anesthesiology & $30(50 \%)$ & \\
\hline Living place & & 0.421 \\
\hline University dormitory & $42(70 \%)$ & \\
\hline Native & $18(30 \%)$ & \\
\hline Average age & $12 \pm 2.1$ & 0.754 \\
\hline
\end{tabular}

\section{Discussion}

Assessment is an integral part of the teaching-learning process, and today assessment for learning has been introduced rather than the assessment of learning that focuses on guiding students' learning rather than classifying and comparing them with each other. Effective assessment not only plays a role in screening students, but it also helps the teacher to evaluate his/her activities; thereby, student learning, and ultimately the achievement of educational goals, is measured. The results of our study showed that $89 \%$ of the students were highly satisfied with the open-book assessment method, which is in line with the findings of the study by Eilertsen and Valdermo (2000). There are various types of student assessment, and studies show that the most common type of test is Multiple Choice

Table 2. The effect of group open-book assessment method in different areas of the questionnaire

\begin{tabular}{|c|c|c|c|c|c|}
\hline Areas & $\begin{array}{l}\text { Strongly } \\
\text { agree }\end{array}$ & Agree & Neutral & Disagree & $\begin{array}{l}\text { Strongly } \\
\text { disagree }\end{array}$ \\
\hline Reducing test fear and anxiety & $93.4 \%$ & $3.3 \%$ & $3.3 \%$ & 0 & 0 \\
\hline Increasing durability and depth of learning & $90 \%$ & $6.6 \%$ & $3.4 \%$ & 0 & 0 \\
\hline Improving speed and facilitating learning & $80 \%$ & $20 \%$ & 0 & 0 & 0 \\
\hline Creating interest and satisfaction & $89 \%$ & $4.3 \%$ & $6.7 \%$ & 0 & 0 \\
\hline
\end{tabular}

Table 3. Comparison of the mean assessment score of the intervention group and the control group

\begin{tabular}{lcc} 
Group & Mean & Standard deviation \\
Intervention & 4.5 & 0.77 \\
\hline Control & 2.2 & 0.85 \\
\hline
\end{tabular}


Questions (MCQ) and especially four-choice questions (Delaram 2008).

Standard MCQ tests are rarely found, and most of these tests have structural errors. Evidence suggests that many of these tests are dumb, and some can be answered without any knowledge. Tarrant et al. (2006) reviewed nursing tests from 2001 to 2005 and evaluated 2270 questions with a checklist. The results showed that $46.2 \%$ of questions had at least one error, and $21 \%$ had more than 2 errors.

A study by Haghshenas et al. (2009) which examined multiple-choice tests at Mazandaran Medical School also showed that $54 \%$ of the multiple-choice tests had one or more structural errors and because of the end-of-semester exam criterion, it prevented deep learning among students.

The results of our study showed that the majority of students believed that the open-book assessment method reduced fear and anxiety, which is consistent with the results of the study by Durning et al. (2016).

Anxiety is an unpleasant state that affects human health and causes many physical and psychological problems (Aschen 1997). Research shows that students' test anxiety levels are high (Karami et al. 2018; Cheraghian et al. 2008; Hancock 2001). Anxiety affects learners' information processing and has a great impact on their academic performance (Pourghane 2016). Therefore, faculty members must use more efficient assessment methods to reduce test fear and anxiety among students.

The findings of the study showed an increase in the scores of the intervention group compared to the control group, and the majority of the students found this method effective in facilitating and accelerating learning (Chan and Mui 2004). Today, we are faced with a world full of evolving and competent students with increasing demands and changing needs; therefore, universities should use effective and efficient assessment methods, and implement high-quality assessment programs to enhance learning (Delaram 2008).

\section{Conclusions}

The open-book assessment method is a useful way to assess learners. The results showed that this assessment method can be effective in deep learning, reduce anxiety, and improve the students' learning speed. Universities should promote students' learning, academic achievement, and motivation through innovative assessment methods.

\section{Acknowledgments}

The authors wish to thank North Khorasan University of Medical Sciences for its financial support to conduct and complete this research. Also we appreciate all the students who helped us with this research.

\section{Disclosure}

The authors declare no conflict of interest.

\section{References}

1. Abdollahi B, Farhadi Amjad F, Ghadimi F. The study of the influential factors on the rate of reliability of teacher evaluation results by students: a mixed research. Educ Measurement Eval Stud 2015; 5: 129-152.

2. Alghamdi NI. Providing insight into assessment practices in medical school at one Saudi Higher Education Institution: an interpretative phenomenological analysis. University of Glasgow, Glasgow 2020.

3. Aschen SR. Assertion training therapy in psychiatric milieus. Arch Psychiatr Nurs 1997; 11: 46-51.

4. Assadi S, Shariati A, Haghighi S, et al. Effects of clinical education and evaluation with portfolio method on nursing students' satisfaction: a clinical trial. J Clin Nurs Midwifery 2014; 3: 70-79.

5. Atashrouz M, Pourmoghadasian AM, Marashi SM. Investigating the teaching quality of faculty members from the perspective of students; the case of branches of Farhangian University in Khuzestan Province. Educ Measurement Eval Stud 2018; 8: 49-79.

6. Chan MY, Mui KW. The use of open book examinations to motivate students: a case study from Hong Kong. World Transactions Eng Technol Educ 2004; 3: 111-114.

7. Cheraghian B, Fereidooni-Moghadam M, Baraz-Pardejani $S$, et al. Test anxiety and its relationship with academic performance among nursing students. Knowledge Health 2008; 3: 25-29.

8. Coker AL, Fisher BS, Bush HM, et al. Evaluation of the Green dot bystander intervention to reduce interpersonal violence among college students across three campuses. Viol Against Women 2015; 21: 1507-1527.

9. Crooks TJ. The impact of classroom evaluation practices on students. Rev Educ Res 1988; 58: 438-481.

10. Delaram M. Evaluation of students by faculty members and educational staff at Shahr-e-Kord University of Medical Sciences in 1386-87. J Med Educ Development 2008; 2: 9-15.

11. Durning SJ, Dong T, Ratcliffe T, et al. Comparing openbook and closed-book examinations: a systematic review. Acad Med 2016; 91: 583-599.

12. Eilertsen T, Valdermo O. Open book assessment: a contribution to improved learning? Stud Educ Eval 2000; 26: 91-103.

13. Feldhusen JF. An evaluation of college students' reactions to open book examinations. Educ Psychol Measurement 1961; 21: 637-646.

14. Haghshenas MVK, Mahmoodi M, Shahbaznezhad L, et al. A study on multiple choice tests in Medical School of Mazandaran University of Medical Sciences. J Med Educ Development Studies Center 2009; 5.

15. Hancock DR. Effects of test anxiety and evaluative threat on students' achievement and motivation. J Educ Res 2001; 94: 284-290. 
16. Karami M, Dehdashti A, Bahrami M. Prevalence of test anxiety among public health students at Semnan University of Medical Sciences in 2017. Short Rep 2018; 17.

17. Klieme E. Policies and practices of assessment: a show case for the use (and misuse) of international large scale assessments in educational effectiveness research. In: International Perspectives in Educational Effectiveness Research. Springer, Frankfurt 2020; 147-181.

18. Komeili GR, Rezai GA. Methods of student assessment used by faculty members of basic medical sciences in Medical University of Zahedan. Iran J Med Educ 2001; 1: 52-57.

19. Msila V. Open book examinations in a distance (teacher) education programme: South African teacher-learners' experiences. Inter J Distance Educ Technol (IJDET) 2011; 9: 1-12.

20. Pakkies NE, Mtshali NG. Students' views on the block evaluation process: a descriptive analysis. Curationis 2016; 39: 1516.

21. Pourghane P. Study of test anxiety among nursing students. Development Strat Med Educ 2016; 3: 1-9.

22. Shahidi M, Atarodi A, Moghimian M. The survey of using learning strategies rate in students. Quarterly Horizon Med Sci 2005; 11: 53-60.

23. Tarrant M, Knierim A, Hayes SK, et al. The frequency of item writing flaws in multiple-choice questions used in high stakes nursing assessments. Nurs Educ Today 2006; 26: 662-671. 